\title{
ON A FEED-WATER HEATER AND FILTER FOR STATIONARY AND LOCOMOTIVE BOILERS.
}

By Mr. George S. Strong, of Philadelphi, U.S.

In most feed-water heaters the purification of the water from matter held both in solution and suspension is to a great extent an accidental circumstance, not contemplated in their design. Where soft waters are in use special attention need not be given to this point, but where hard water prevails too much attention cannot possibly be paid to it.

Many devices have been used to purify the water before entering the boiler. Some seek to precipitate the dissolved salts by chemical means, such as the addition of carbonate of soda or carbonate of lime, and then either allow the water to settle or pass it through a filter. It is unnecessary to urge the inconvenience of any chemical method; the drawbacks are only too apparent.

In designing the feed-water heater now to be described, the writer paid special attention to the separation of all matters, soluble and insoluble; and he has succeeded in passing the water to the boilers perfectly pure, and free from any substance which would cause scaling or coherent deposit. His attention was more particularly called to the necessity of extreme care in this respect, through the great annoyance suffered by steam users in the central and western parts of the United States, where the water is heavily charged with lime. Very simple and even primitive boilers are there used; the most necessary consideration being handiness in cleaning, and not the highest evaporative efficiency. These boilers are therefore very 
wasteful, only evaporating, when covered with lime scale, from two to three pounds of water with one pound of the best coal, and requiring cleaning once a week at the very least. The writer's interest being powerfully aroused, he determined if possible to remedy these inconveniences; and accordingly he made a careful study of the subject, and examined all the heaters then in the market. He found them all, without exception, insufficient to free the feed water from the most dangerous of impurities, namely the sulphate and the carbonate of lime.

That this assertion is correct may be proved by the following quotation from the guarantee given by the Berryman Heater Company:- " I guarantee every heater to deliver the feed water to the boilers at a uniform temperature of $200^{\circ}$ Fahr. and above, using exhaust steam, and also to free said water from all impurities (with the exception of salt, sulphate of lime, and such other acids as cannot be separated except by evaporation), and that its use will not in any way interfere with the use of the exhaust steam for heating purposes, and I invite orders subject to such guarantee."

Carbonate of lime is almost insoluble in pure water, but it is soluble to a great extent in water containing carbonic acid gas in solution. Thus dissolved, it gives rise to what chemists call in their analysis reports "temporary hardness." This temporary hardness disappears when the water is boiled, because the carbonic acid gas is expelled in boiling, and the carbonate of lime is precipitated; causing the water to become milky in appearance, from the finely powdered chalk suspended in it.

"Permanent hardness" arises from the presence of sulphate of lime, or sulphate of magnesia. At the ordinary temperature of boiling water, and at atmospheric pressure, a portion of the sulphate of lime is deposited, though from a cause quite different from that of the precipitation of the carbonate. It has been found that sulphate of lime is much more soluble in cold water than in hot, which is a reversal of the usual order of things with soluble salts; and accordingly water containing this substance may be quite freed from it by heating to a sufficiently high temperature. 
The following Table shows the solubility of sulphate of lime in water at different temperatures:-

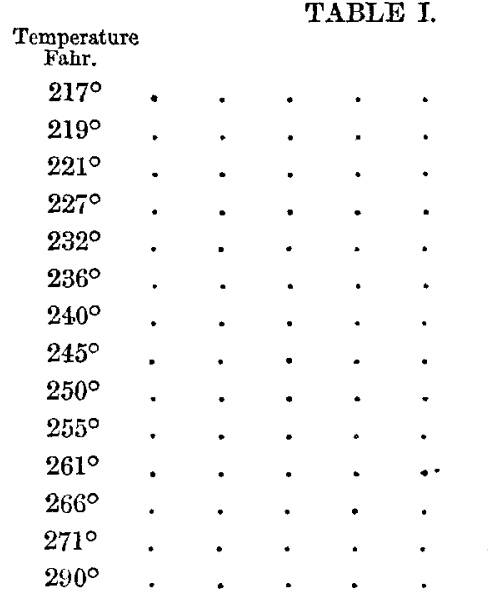

$$
\begin{aligned}
& \text { Sulphate of Lime. } \\
& \text { Percentage held in Solution. } \\
& 0.500 \\
& 0.477 \\
& 0 \cdot 432 \\
& 0 \cdot 395 \\
& 0 \cdot 355 \\
& 0 \cdot 310 \\
& 0 \cdot 267 \\
& 0 \cdot 226 \\
& 0 \cdot 183 \\
& 0 \cdot 140 \\
& 0 \cdot 097 \\
& 0.060 \\
& 0 \cdot 023 \\
& 0.000
\end{aligned}
$$

The reason of sulphate of lime becoming insoluble on heating seems to be the gradual decomposition of the hydrate. Anhydrous calcic sulphate is insoluble in water, but if it be hydrated it then dissolves; hence, by causing the water to attain a sufficiently high temperature, the dehydration is effected and the anhydrous sulphate is deposited.

Sulphate of magnesia, the remaining impurity which commonly occurs in water, does not precipitate on boiling or heating the water. Carbonate of magnesia behaves in the same way as carbonate of lime, coming down as soon as the carbonic acid is expelled.

Taking these facts, well known to all chemists, as the basis of his operations, the writer perceived that all substances likely to give trouble by deposition would come down at a temperature of about $250^{\circ} \mathrm{F}$.

His plan was therefore to make a feed-water heater in which the water could be raised to that temperature before entering the boiler. Now by using the heat from the exhaust steam, the water may be raised to between $208^{\circ}$ and $212^{\circ} \mathrm{F}$. It has yet to be raised to $250^{\circ} \mathrm{F}$.; and for this purpose the writer saw at once the advantage that would 
be attained by using a coil of live steam from the boiler. This device does not cause any loss of steam, except the small loss dne to radiation, since the water in any case would have to be heated up to the temperature of the steam on entering the boiler. By adopting this method, the chemical precipitation, which would otherwise occur in the boiler, takes place in the heater; and it is only necessary now to provide a filter, which shall prevent anything passing that can possibly cause scale.

The heater, being subject only to a strictly determinate temperature, does not cause the precipitate to adhere to the tubes or metal, so that scale cannot be formed in it; since, to produce sufficient coherence to form scale, it is necessary that the metal should be heated considerably above the temperature of the water, in fact that the flame of the fire should play on one side of it.

Having explained as shortly as is possible the principles on which the system is founded, the writer will now describe the details of the heater itself.

In Figs. 1 to 3, Plate 75, are shown an elevation, a vertical section, and a sectional plan of the heater. The cast-iron base $A$ is divided into two parts by the diaphragm B. The exhaust steam enters at $C$, passes up the larger tubes $\mathrm{D}$, which are fastened into the upper shell of the casting, returns by the smaller tubes $\mathrm{E}$, which are inside the others, and passes away by the passage $F$. An enlarged section of the upper part of the tubes is shown in Fig. 4, in which the course of the exhaust steam is shown by the arrows. The inner tube only serves for discharge. It will be seen at once that this arrangement, while securing great heating surface in a small space, at the same time leaves perfect freedom for expansion and contraction, without producing the slightest strains. The free area for passage of steam is arranged to be one-and-a-half times that of the exhaust pipe, so that there is no possible danger of back pressure. The malleable iron shell $\mathrm{G}$, connecting the stand $\mathrm{A}$ with the dome $\mathrm{H}$, is made strong enough to withstand the full boiler pressure. An ordinary casing $J$, of wood or other material, prevents loss by radiation of heat. The cold water from the pump passes into the 
heater through the injector arrangement $K$, and coming in contact with the tubes $D$ is beated; it then rises to the coil $\mathbf{L}$, which is supplied with steam from the boiler, and thus becomes further heated, attaining there a temperature of from $250^{\circ}$ to $270^{\circ} \mathrm{F}$., according to the pressure in the boiler. This high temperature causes the separation of the dissolved salts; and on the way to the boiler the water passes through the filter M, becoming thereby freed from all precipitated matter, before passing away to the boiler at $\mathrm{N}$. The purpose of the injector $K$, and the pipe passing from $O$ to $K$, is to canse a continual passage of air or steam from the upper part of the dome to the lower part of the heater, so that any precipitate carried up in froth may be again returned to the under side of the filter, in order more effectually to separate it, before any chance occurs of its passing into the boiler.

The filter consists of wood charcoal in the lower half, and bone black above, firmly held between two perforated plates, as shown. After the heater has been in use for from three to ten hours, according to the nature of the water used, it is necessary to blow out the heater, in order to clear the filter from deposit. To do this, the cock at $R$ is opened, and the water is discharged by the pressure from the boiler. The steam is allowcd to pass through the heater for some little time, in order to clear the filter completely. After this operation all is ready to commence work again. By this means the filter remains fit for use for months, without change of the chareoal.

Where a jet condenser is used, either of two plans may be adopted. One plan takes the feed water from the hot well, and passes the exhaust from the feed pumps through the heater, using at the same time an increased amount of coil for the live steam. By this means a temperature of water is attained, high enough to cause deposition, and at the same time to produce decomposition of the oil brought over from the cylinders. The other plan places the heater in the line of exhaust from the engine to the condenser, also using a larger amount of coil. Both these methods work well. The writer sometimes uses the steam from the coil to work the feed pump; or, if the heater stands high enough, it is only necessary to make a 
connection with the boiler, when the water formed by the condensation of the steam runs back to the boiler, and thus the coil is kept constantly at the necessary temperature.

In adapting this system to locomotive boilers, the heater is made in the form of a saddle, to which is bolted a dome containing the coil and filter. A pipe, taken from the bottom of the right-hand blast nozzle, communicates with the exhaust chamber of the heater, and from the discharge side passes again to the same nozzle, where, by the construction of the nozzle, it is passed out to the atmosphere with the main body of steam. By this method no steam is drawn from the blast, except that actually required to heat the water. This steam of course condenses; but care is taken to draw off the water formed, so as not to discharge water at the blast. The amount condensed is 20 per cent. of the whole steam used. It will be observed that by this construction there is perfect freedom for contraction and expansion.

The author may be allowed to mention one or two cases where his purifier has done good service, and indeed has been found quite invaluable. The first of the stationary heaters was constructed in the summer of 1879 , and was attached to a battery of boilers at the Eliza Furnace, in Pittsburg, owned by Lauchlin and Co. These boilers deposited scale very fast, so fast that it was necessary to chisel the scale off every fortnight when they were worked during the day, and every week when kept going constantly. After having run with the heater for a fortnight, the boilers were opened, and the scale was found quite loose, and came away quite easily. They were then run one month, and so little scale was formed that it was unnecessary to remove it. They now run six months continuously before requiring any cleaning whatever.

Another heater was fitted to a battery of tubular boilers, using water from New York Bay, or from an adjoining salt marsh. These boilers had constantly burned out from six to ten tubes per week, and it was impossible to clear out the scale. It formed so hard in the tubes that it could not be driven out: it would even stand the steam pressure after the iron was completely burned array, and then would break in two like a pipe-stem. After using the heater 
for some weeks, the scale was found to be quite soft, and a plug could be driven right through the tube, carrying the scale before it. These boilers are now worked with very little difficulty.

The writer has now had wide experience with this heater in the United States, using every kind of water, and has obtained good results in all cases : and having recently made arrangements for its manufacture in this country, he doubts not he will be able ere long to point to equally satisfactory results in Europe.

Discussion on Feed-Water Heater and Filter.

The Prusudent said Mr. Strong was present, having crossed the Atlantic on purpose to attend the meeting; and the members would be glad to hear any observations from him before the discussion commenced.

Mr. Strong wished to edd a word about the process of blowing-off. By opening the cock $\mathrm{R}$ and blowing the live steam downwards from the top through the filter, it blew all the water ont of the heater, and drove out the sulphate and the carbonate ; so that it was not necessary to change the filter very often. At Pittsburg, where the water was very bad, a heater had run for six months without changing the filter or opening the boilers. Frormerly it was necessary to open the boilers once every two weeks.

Fig. 5, Plate 75, showed a simpler arrangement of the tubes, which he was now introducing. Instead of having one tube within another, there was a single tube, divided into two parts, nearly up to the top, by a diaphragm shaped like an $S$ in plan, which was sprung into the tubc. The end of the diaphragm projected below the tube, and was bent towards the entering steam; and the effect was that the steam passed up one side of the diaphragm, and down the other. 
With regard to locomotive practice, the apparatus had not yet been started in this country, but Fig. 6, Plate 76, showed the form that it would take as applied to an engine on the Metropolitan Railway. There were two heaters A, placed one on each side of the locomotive, between the two pairs of driving wheels, and sunk in the tank, but within a sheet-iron casing to prevent their being chilled by the water. They were connected together, and worked either by pump or injector through the pipe $B$. The heating was done by taking the exhaust pipe $\mathrm{C}$ through the heater on its way to the tank, depending on the effect of the blast to keep the heater sufficiently charged with exhaust steam. Another plan was to fit the heater as an extra dome on the top of the boiler, depending entirely on the live steam within the coil to do the heating. The water was taken from the injector at about $150^{\circ} \mathrm{Fahr}$., raised to $250^{\circ}$ by the live steam, and then passcd direct through the filter to the boiler. This arrangement acted very well as a purifier for water, but did not effect any special economy in heat. In every case the heater could be adapted to suit any special conditions. Fig. 7, Plate 77, showcd another form of heater and filter adapted to the standard goods engine of the Great Southern and Western Railway of Ireland. One heater was placed on each side, between the leading and contral driving wheels. The exhaust steam was led from the smoke-box throngh the pipe A into the heater and back again, as already described, and as in use on the American locomotives. The water in this instance was fed by an injector through the pipe $B$, and the water was heated and filtered as already described, and as shown in Fig. 2 for stationary heaters. The two heaters were coupled by a pipe C, passing over the top of the boiler, close to the base of its dome; and the water was fed from this pipe through a $T$ joint into the boiler, in the usual manner of locomotive practice.

Mr. W. Richandson observed that in the discussion on Mr. Marten's paper on Boilers (Proceedings 1870, p. 214) he had explained the method adopted at Messrs. Platt's works at Oldham in filtering feed-water for boilers. Having there to use sewage water continuously, they had great difficulty and trouble with the mud 
deposit: they were not much troubled with lime, but the mud dried in the boilers. They then adopted a filter similar to the one shown, only it was in a strong casing with a cavity at the top and bottom, and the space between the two cavities was filled with animal charcoal. When the water was passed through the filter into the boilers, the mud was deposited among the charcoal. Frequently, perhaps twice a day, they revorsed the current, in the way that had been explained, by opening the tap at the bottom and letting the boiler pressure drive some of the clean water back through the filter, so as to cleanse it. That plan had been going on for twenty years, and it had had the effect of keeping the mud out of the boilers; but the water was only heated as high as the exhaust steam would heat it-perhaps to $210^{\circ}$ Fahr.

Mr. D. GREIG had had considerable experience in feed-water heating for portable boilers; and he thought that the extra heating described in the paper appeared to be a cure for the evils which had been felt, and that Mr. Strong was on the right track.

Mr. W. E. RroH desired to call attention to the remark upon p. 543: "The other plan places the heater in the line of exhaust from the engine to the condenser, also using a larger amount of coil." It would perhaps be scarcely necessary to remind the author that so little value was to be attached to the heat in the exhaust pipe of an engine with any pretensions to economical working, that such an arrangement would be almost if not quite valueless in engines using hot-well water for feed. He generally found that the temperature in the exhanst pipe of an engine working well and with high expansion was not more than one could bear with the hand, say something like $125^{\circ}$. The tendency with most English Boiler Insurance Companies was very strongly to deprecate the use of water which had been through the cylinders, and to use fresh cold water for feeding. Of course in such cases the arrangement of a heater in the exhaust pipe would be much more beneficial.

Mr. T. Aвbotr said, in what littlo experience he had had as to. 
the difficulties connected with feed-water, he had found they wore greatest where the men working the boilers were the least skilled; consequently it was very important that a feed-water heater should be as simple as possible. The apparatus explained in the paper seemed to be very good in that respect; but so far as he could see from the drawing, there would be considerable difficulty in withdrawing the filter itself from the casing, which would have to be done possibly once in every three or four months. There seemed a good deal of disconnecting to be done, bolts to undo, \&c., in order to get the filter out. If that could be easily got over, he had no doubt it would be a great success.

The President said there was one thing in the paper that struck him at once, and he had hoped that some one would have drawn attention to it. It was stated, p. 539, that in the central or western part of the United States the water was heavily charged with lime, and that the quantity of water evaporated was only from 2 to 3 lbs. for every pound of the best coal. That water must certainly be very exceptional, requiring a large amount of filtering apparatus. In this country they generally had better water than that; but in certain cases where there was a large quantity of sulphate of lime, sulphate of magnesia, and carbonate of lime, he imagined that a filter would be very effective. He was in hopes that some information would be given as to experience of its use in this country.

Mr. JEREmiar Grad had always understood that the term "temporary hardness" was applied to carbonate of lime, which was precipitated in boiling, as pointed out in the paper; and that the term "permanent hardness" was applied, as the author had put it, to sulphate of lime and sulphate of magnesia, which were not separated from the water on boiling. But the whole principle of the paper seemed to bo founded on what was to him a new fact-that all these substances were precipitated by the addition of another $50^{\circ}$ of temperature. Tho principle of the apparatus was entirely dependent on that fact; and he should like to know whether the experiments which had determined that fact had been made by the author himself, or whether 
it was admitted and relied upon by the chemists of this and other countries. If so, then it appeared to him that the author's case was pretty well proved. As a piece of mechanical construction, it seemed to him that the heater was extremely ingenious and well contrived; almost all the parts were circular and symmetrical, and he could hardly conceive a better arrangement for accomplishing what the author desired to effect.

Mr. Charles Cochrane said it seemed to him that, generally speaking, with regard to that class of beater, the water produced by the condensation of the steam was unnecessarily allowed to run ta waste. It was becoming a matter of greater and greater importance that they should have practically pure water for their boilers; and no better means existed than that of condensing the exhaust steam which came from the engines. He was aware that there was an objection to doing so, namely that the steam brought over with it a certain amount of acids, which certainly did canker and eat the boilers. For nearly twenty years, having experienced that difficulty, his firm had followed the plan of using a very small proportion of caustic soda in the boilers; and they had never been troubled since. They folt it to be a most important point to save every drop of water coming from the engine, and to use it over and over again; and only to use the water supplied from extrancous sources to make up the deficiency arising in the circulation.

Mr. Huan Lee Patrinson said, in reply to Mr. Head, that it was. a well known fact in chemistry that sulphate of lime was rendered insoluble at high temperatures.*

* The following additional information has since been kindly furnished by Mr. Pattinson. "The solubility of sulphate of lime in water diminishes as the temperature rises. At ordinary temperatures pure water dissolves about 150 grains of sulphate of lime per gallon; but at a temperature of $255^{\circ}$ Fahr., at which the pressure of steam is equal to about 2 atmospheres, only about 40 grains per gallon are held in solution. At a pressure of 3 atmospheres, and temperature of $302^{\circ}$ Fahr., it is practically insoluble. The point of maximum solubility is about $95^{\circ} \mathrm{Fahr}$. The presence of magnesium chloride or of calcium chloride in. 
Mr. Strona said that, by means of this heater, with a vacuum of 26 in. of mercury in the condenser, he got a temperature of about $135^{\circ} \mathrm{Fahr}$. in the heater from the exhaust, and about $150^{\circ}$ with a vacuum of $22 \mathrm{in}$. Thus by using the exhaust steam to heat the cold feed-water he gained the difference between say $60^{\circ}$ and $140^{\circ}$, which was worth something like 4 or 5 per cent. of the fuel used. Again, if he took the water from the hot-well, at a temperature of from $90^{\circ}$ to $100^{\circ}$, he still got a further $40^{\circ}$ of increased temperature by using the condensed steam, which was worth something like $2 \frac{1}{2}$ or 3 per cent. of the fuel. At the same time, by passing the water from the hotwell through the apparatus, he got rid, not only of the lime in the water, but of the cylinder oil which was in the hot-well. With regard to the sulphate of lime, which seemed to be the only point that was in question, he found, when he commenced his experiments in the United States, that chemists generally did not agree that sulphate of lime was separated by boiling. Their experience had been derived from merely raising water to its boiling point, or $212^{\circ}$, at which temperature the sulphate of lime had not been separated. It was only after experimenting with his apparatus that he became thoroughly satisfied that it was separated at $250^{\circ}$ Fahr. At Pittsburg, where there was a good deal of sulphuric acid in the water, and where there was a good deal of pitting as well as scale in the boilers, not only was the scale stopped, but the corrosion also, from the fact that the sulphate of lime, and the sulphuric acid, and all the other minerals and acids, seemed to combine with one another at a high temperature. In reference to that subject, he might mention that brass tubes were used in these heaters. Where the water reached a high temperature in a heater with iron tubes, it seemed to take a particular line across the vertical tubes and eat them through there; it had therefore been found necessary to use brass or copper tubes in the heaters, iron tubes not lasting more than

water diminishes its power of dissolving sulphate of lime; while the presence of sodium chloride increases that power. As an instance of the latter fact, we find a boiler works much cleaner which is fed alternately with fresh water and with brackish water pumped from the Tyne when the tide is high, than one which is fed with fresh water constantly." 
eighteen months. He had been using paint, made of boiled linseed oil and red lead, to coat the inside of the heater shell, putting on about four coats, in order to prevent the acid from taking hold of the iron shell. In some cases, where the acid had been very bad, it had been necessary to make the heater of brass and copper throughout.

With regard to changing the filter, with all his heaters he arranged a travelling crane over the top, with a differential pulley and wheel running on a bar; and by this means he handled the dome and the filter very readily. With a 600 H.P. engine, he had taken the dome off, lifted the filter out, washed out the inside with hose, and replaced it, in less than two hours. The tube-plate was made of cast-iron, and the tubes were screwed into it, usually with sixteen threads to the inch. The Table of percentages, p. 541, was taken from Burgh's Marine Engineering. He had found in actual practice that it was not necessary to use so high a temperature as $290^{\circ} \mathrm{Fahr}$. to get separation: $250^{\circ}$ or $260^{\circ}$ gave practically pure water, though not chemically pure. 
FEED-WATER HEATER AND FILTER. Plate 75.

Heater for Stationary Boilers.

Fig. 1. Elevazion.

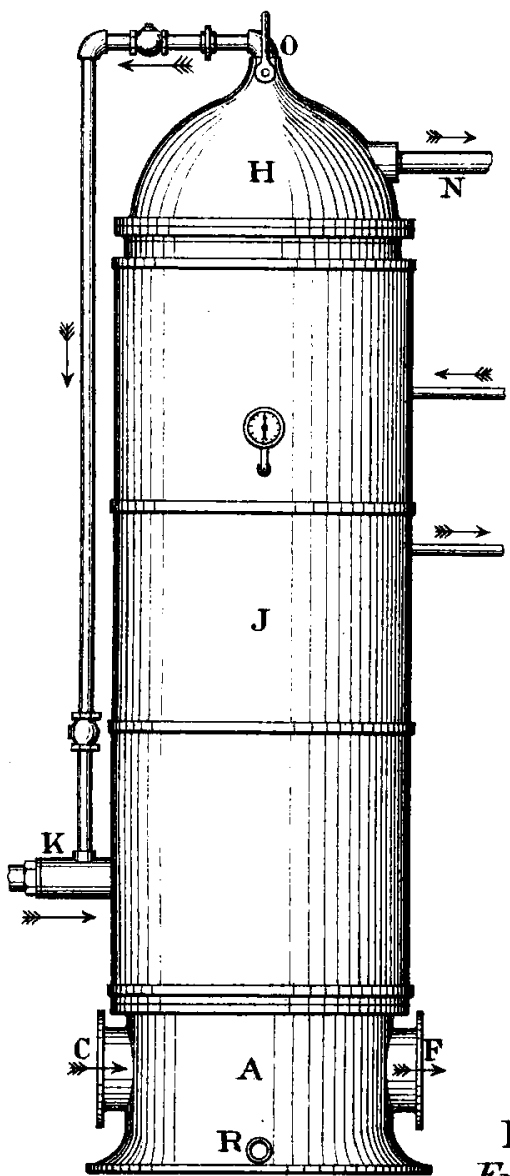

Fig. 5.

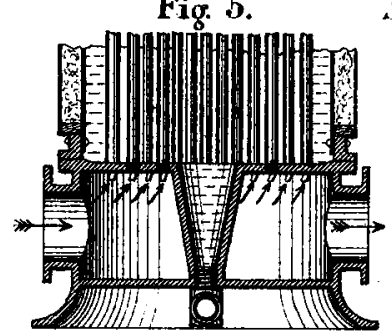

Scate $1 / 48^{\text {th }}$
Fig. 2.

Vertical Section.

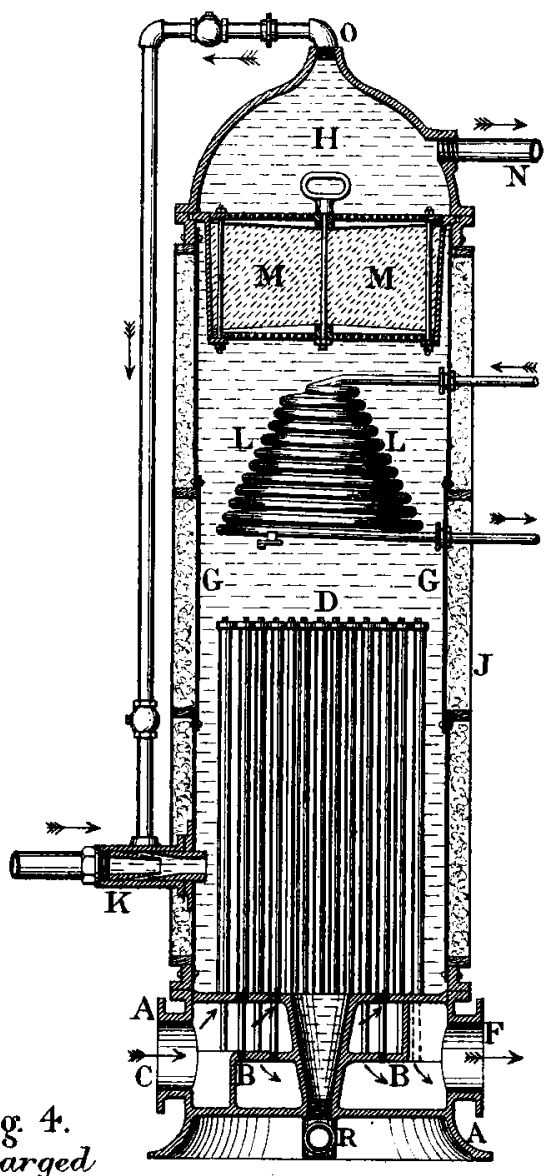

Section of Tubes. Fig 3 Transwass Scotion.
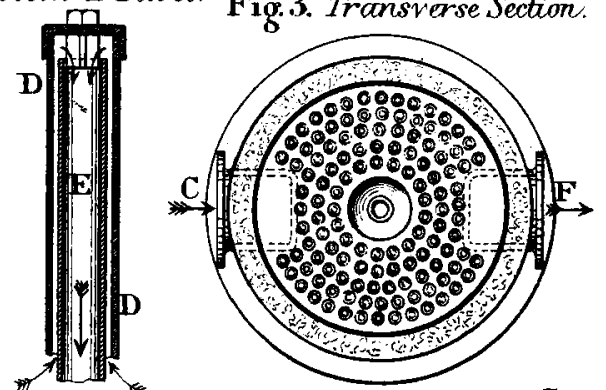

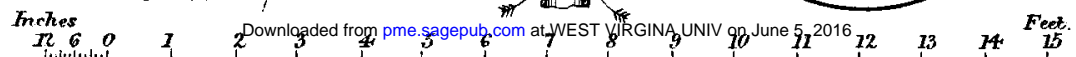


Fig: 6. Hecales as applied to Side-Tank Eongine, Metropolitan Rreiluat.

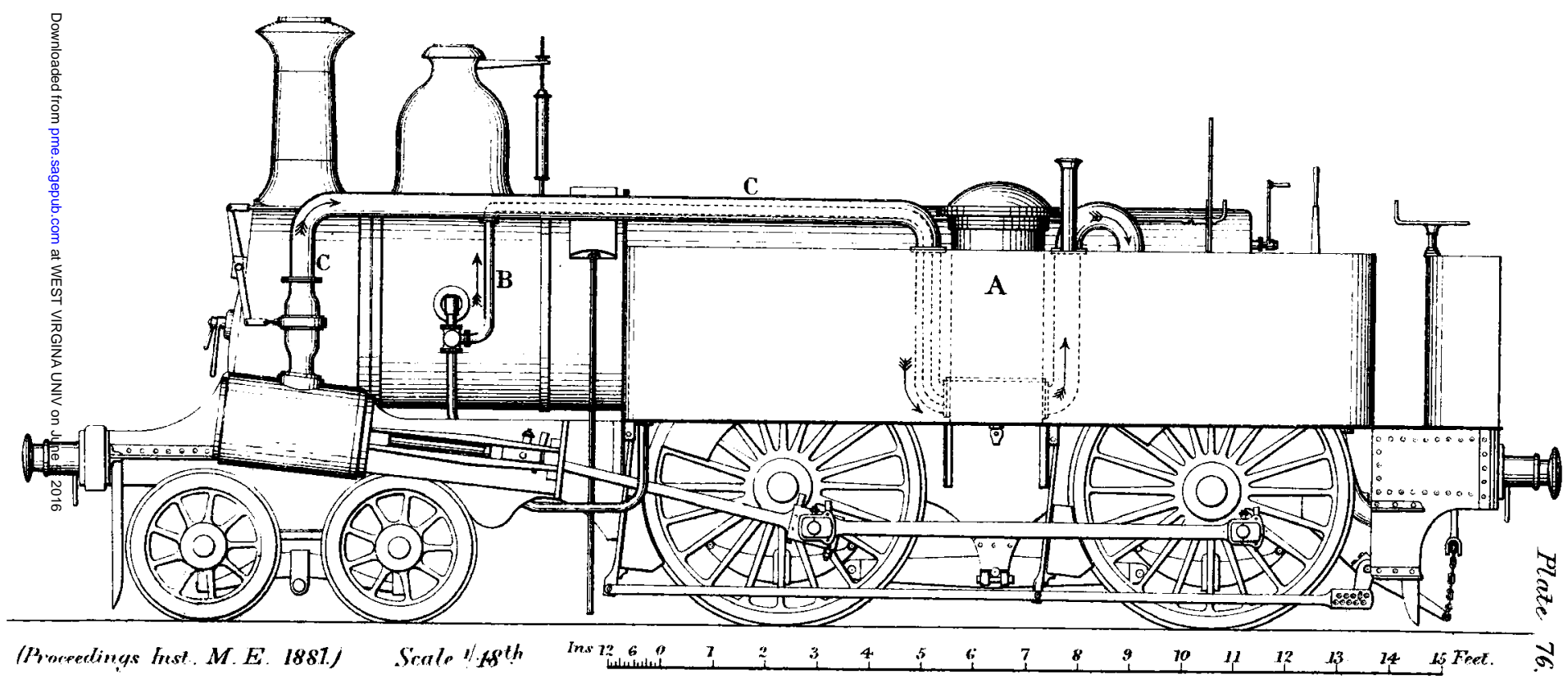




\section{FEED-WATER HEATER AND FILTER.}

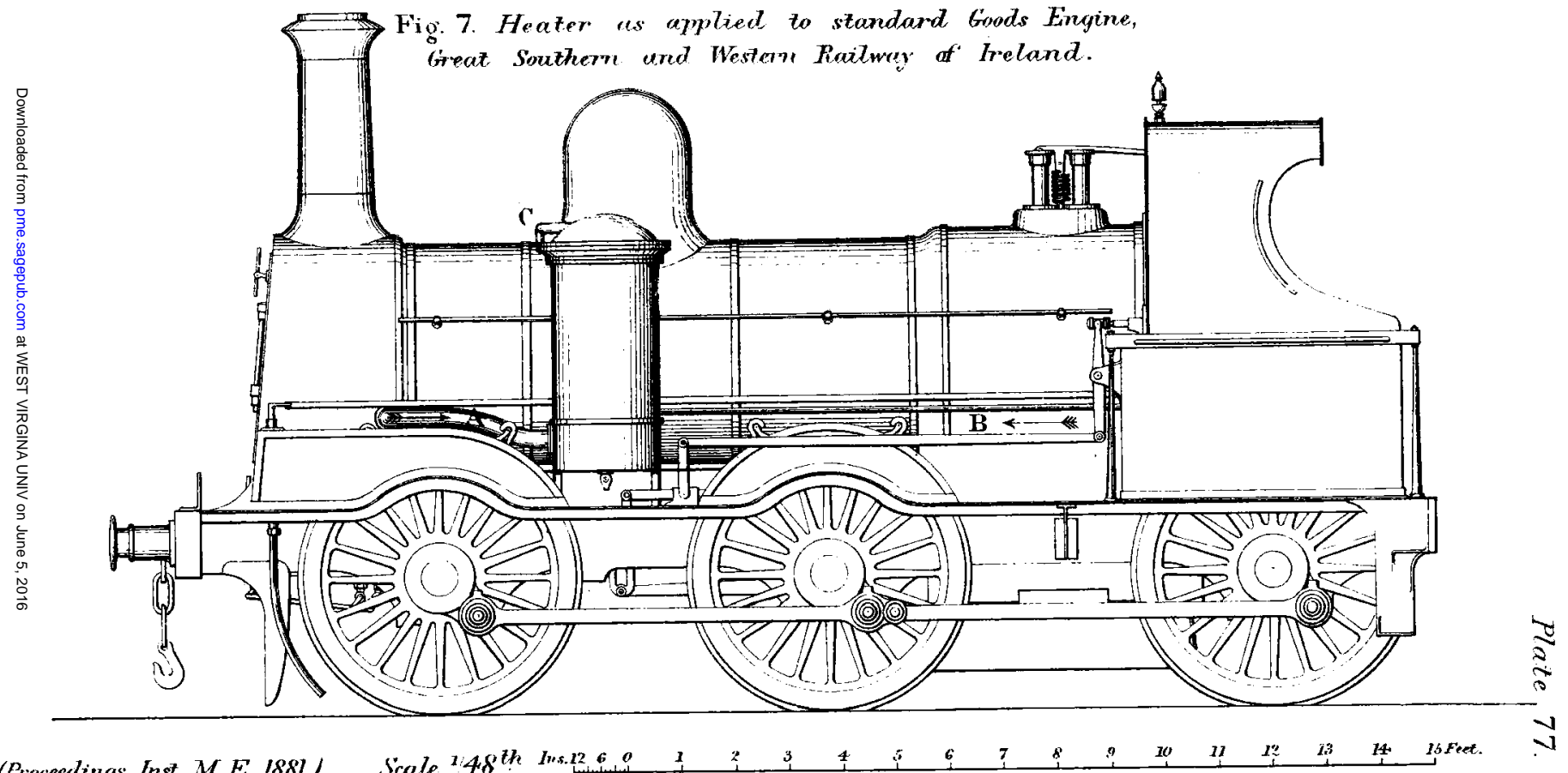

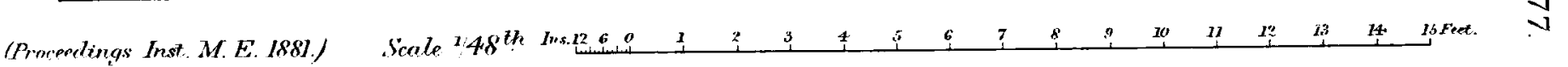

